\title{
Identifikasi Jamur Kontaminan yang Bersifat Xerofilik pada Lada Bubuk
}

\author{
Identification of Fungi Contaminants Are \\ Santika Widowati, Kartinah W.*, dan Guruh Sri Pamungkas \\ Program Studi D-III Analis Kesehatan Fakultas Ilmu Kesehatan Universitas Setia Budi \\ *Corresponding author: kartinahws@yahoo.com
}

\begin{abstract}
ABSTRAK
Lada merupakan salah satu jenis rempah yang cukup penting, baik ditinjau dari peranannya sebagai penyumbang devisa negara maupun kegunaannya yang khas dan tidak dapat digantikan oleh jenis rempah lainnya. Pada proses pengolahan lada yang masih dilakukan dengan cara yang kurang higienis, risiko produk terkontaminasi oleh jamur selama proses pengolahan lada bubuk masih sangat besar, khususnya jamur xerofilik, yaitu jamur yang mampu tumbuh pada produk kering atau kadar air yang rendah. Penelitian ini bertujuan untuk mengetahui adanya jamur xerofilik pada lada bubuk dan mengetahui spesies jamur xerofilik apa saja yang berpotensi sebagai penghasil toksin pada lada bubuk.

Metode yang digunakan untuk pemeriksaan yaitu metode taburan. Sampel lada bubuk di encerkan dengan menggunakan aquades steril, dengan pengenceran $10^{-1}, 10^{-2}$, dan $10^{-3}$, masing-masing di inokulasikan ke dalam medium DG18 pada cawan petri steril dan diinkubasi selama 5-7 hari. Kemudian di identifikasi secara makroskopis dan mikroskopis.

Hasil identifikasi menunjukan lada bubuk terkontaminasi jamur xerofilik. Spesies jamur xerofilik yang terdapat pada lada bubuk yaitu Aspergillus candidus, Aspergillus ochraceus, Aspergillus fumigatus, Eurotium herbariorum, Aspergillus tamarii, Eurotium chevalieri, Aspergillus penicilloides, Aspergillus niger, dan Aspergillus oryzae. Dari 9 spesies jamur yang ditemukan, 6 diantaranya dapat berpotensi sebagai penghasil mikotoksin.
\end{abstract}

Kata kunci : lada bubuk, kontaminan, jamur xerofilik

\section{ABSTRACT}

Pepper is one of the types of spices that is significant both in terms of its role as a contributor offoreign exchange for the country and its purpose is specific and cannot be replaced by the type of the other spices. In processing the pepper is still carried out in a way that is less hygienic, the risk of contaminated products by fungi during processing the pepper powder is still very large, especially fungi xerophilic, namely fungi that are able to grow on the dry product or low water levels. This research aims to know the existence of fungixerophilic on the pepper powder and know what xerofilik fungal species that potentially as producer of the toxin on the pepper powder.

The method used for checking the finishing method. Samples of ground pepper in encerkan using sterile aquades, with dilution are 10-1, 10-2, and 10-3, each in inoculation into the medium DG18 on the cup petri sterile and incubation for 5-7 days. Then in the identification by makroskopis and microscopic vermin.

The results of the identification of the show pepper powder contaminated with fungi xerophilic. Fungal xerophilic species found on the pepper powder are Aspergillus candidus, Aspergillus ochraceus, Aspergillus fumigatus, Eurotium herbariorum, Aspergillus tamarii, Eurotium chevalieri, Aspergillus penicilloides, Aspergillus niger and Aspergillus oryzae. From 9 species of fungifound, 6 of them can potentially as producer mikotoksin.

Keywords: pepper powder, contaminants, fungi xerophilic

\section{PENDAHULUAN}

Lada merupakan salah satu jenis rempah yang cukup penting, baik ditinjau dari peranannya sebagai penyumbang devisa negara maupun kegunaannya yang khas dan tidak dapat digantikan oleh jenis rempah lainnya (Hidayat et al., 2009). Masyarakat pada zaman sekarang lebih memilih menggunakan lada bubuk dibandingkan biji lada yang masih utuh, karena kepraktisannya sehingga mempermudah dalam penggunaannya.

Lada bubuk biasanya digunakan sebagai bumbu masak, penambah cita rasa pada makanan, dan sebagai obat tradisional. Pada 
proses pengolahan lada yang masih dilakukan dengan cara yang kurang higienis, risiko produk terkontaminasi oleh jamur selama proses pengolahan lada bubuk masih sangat besar. Mulai dari perontokan buah lada yang dilakukan dengan cara diinjak-injak, penjemuran yang sangat sederhana, peralatan dan ruangan yang kurang bersih, memungkinkan terjadinya kontaminasi oleh mikroorganisme, terutama jamur (Hidayat et al., 2009). Jamur xerofilik merupakan kelompok jamur yang dapat hidup pada kondisi kering (Rahayu, 2007).

Diantara beberapa jamur xerofilik dapat menghasilkan mikotoksin yang dapat menyebabkan berbagai macam penyakit yang berbahaya bagi kesehatan, bahkan hingga kematian.

Jamur xerofilik adalah kelompok jamur yang senang hidup pada kondisi kering $\left(\mathrm{a}_{\mathrm{w}}\right.$ rendah). Bakteri tidak dapat tumbuh pada $\mathrm{a}_{\mathrm{w}}<$ 0,95 , namun tidak demikian halnya dengan jamur. Jamur yang dapat tumbuh pada $\mathrm{a}_{\mathrm{w}} 0,90$ 0,80 termasuk dalam jamur xerotoleran, sedangkan jamur yang dapat tumbuh pada $\mathrm{a}_{\mathrm{w}}<$ 0,80 termasuk dalam jamur xerofilik. Sebagai contoh, selai dan jelli yang memiliki $\mathrm{a}_{\mathrm{w}} 0,85$ 0,75 masih dapat diserang oleh jamur xerofilik (Pitt dan Hocking, 2009). Pengaruh jamur xerofilik bagi kesehatan dari beberapa spesiesnya yaitu dapat menghasilkan mikotoksin yang dapat menyebabkan mikotoksikosis pada manusia maupun hewan (Maryam, 2014).

Medium DG18 digunakan untuk identifikasi jamur dari makanan kering dan setengah kering, termasuk buah, rempah-rempah, sereal, kacang, daging, dan ikan (Acumedia, 2011). Keuntungan menggunakan medium DG18 yaitu mengandung liserol yang berfungsi sebagai sumber karbon dan membuat konsentrasi air menjadi 18\%.

\section{METODE PENELITIAN}

\section{Prosedur Kerja}

1. Persiapan Sampel

Disiapkan 4 sampel lada bubuk A, B, C dan
D sebanyak 10 gram. Disiapkan 4 erlemeyer yang berisi $90 \mathrm{ml}$ aquadest steril. Disiapkan 12 cawan petri steril dan 8 tabung reaksi steril. Dituangkan 10 gram sampel A, B, C, dan D ke dalam erlenmeyer yang berisi $90 \mathrm{ml}$ aquadest steril, lalu dihomogenkan. Dilakukan pengenceran sampai dengan $10^{-3}$. Dipipet $1 \mathrm{ml}$ suspensi dari setiap pengenceran, kemudian dilakukan inokulasi secara taburan kedalam cawan petri steril secara aseptis. Dituangkan medium DG18 pada cawan petri steril. Di-inkubasi pada suhu kamar selama 5 sampai 7 hari. Koloni jamur yang tumbuh pada medium DG18 diamati secara makroskopis dan mikroskopis. Diamati secara makroskopis pada jamur didalam cawan petri dengan cara melihat bentuk dan warna koloni, diamati pada permukaan atas dan permukaan bawah cawan petri. Diamati secara mikroskopis dengan cara membuat preparat jamur menggunakan cat Lactophenol Cotton Blue kemudian diamati dengan mikroskop.

\section{Persiapan Blangko}

a. Blangko Udara

Medium DG18 dituang dalam cawan petri steril, kemudian medium dibuka selama bekerja dalam entkas. Setelah pekerjaan selesai cawan petri ditutup kembali dan diinkubasi pada suhu kamar selama 5-7 hari.

\section{b. Blangko Pengencer}

Pipet $1 \mathrm{ml}$ aquadest steril, kemudian dimasukan ke dalam cawan petri. Cairkan medium DG18 kemudian dituang ke dalam cawan petri, biarkan hingga padat kemudian diinkubasi pada suhu kamar selama 5-7 hari.

\section{c. Blangko Media}

Media DG18 dibuat pada cawan petri steril, diinkubasi pada suhu kamar selama 5-7 hari.

\section{HASIL DAN PEMBAHASAN}

\section{A. Hasil Identifikasi}

Hasil identifikasi jamur ditampilkan di Tabel 1-4, secara makroskopis di Gambar 1-4, dan secara mikroskopis di Gambar 5. 
Tabel 1. Hasil identifikasi jamur xerofilik dari sampel A (lada bubuk bermerk) pada medium DG18

\begin{tabular}{cl}
\hline Sampel & \multicolumn{1}{c}{ Jamur } \\
\hline $\mathrm{A}$ & Aspergillus candidus \\
& Aspergillus ochraceus \\
& Aspergillus fumigatus \\
& Eurotium herbariorum \\
\hline
\end{tabular}

Tabel 2. Hasil identifikasi jamur xerofilik dari sampel B (lada bubuk bermerk) pada medium DG18

\begin{tabular}{cl}
\hline Sampel & \multicolumn{1}{c}{ Jamur } \\
\hline $\mathrm{B}$ & Aspergillus tamarii \\
& Aspergillus penicilloides \\
& Eurotium chevalieri \\
\hline
\end{tabular}

Tabel 3. Hasil identifikasi jamur xerofilik dari sampel C (lada bubuk tidak bermerk) pada medium DG18

\begin{tabular}{cl}
\hline Sampel & \multicolumn{1}{c}{ Jamur } \\
\hline $\mathrm{C}$ & Aspergillus tamarii \\
& Aspergillus niger \\
& Aspergillus oryzae \\
& Aspergillus penicilloides \\
& Eurotium chevalieri \\
\hline
\end{tabular}

Tabel 4. Hasil identifikasi jamur xerofilik dari sampel D (lada bubuk tidak bermerk) pada medium DG18

\begin{tabular}{cc}
\hline Sampel & Jamur \\
& Aspergillus niger \\
Aspergillus tamarii &
\end{tabular}

Gambar 1. Koloni sampel A pada cawan petri permukaan atas (kiri), pada permukaan bawah (kanan), (a) Aspergillus candidus, (b) Aspergillus ochraceus, (c) Aspergillus fumigatus, (d) Eurotium herbariorum

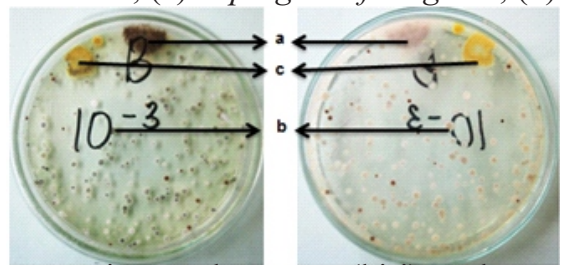

Gambar 2. Koloni sampel B pada cawan petri permukaan atas (kiri), pada permukaan bawah (kanan), (a) Aspergillus tamarii, (b) Aspergillus penicilloides, (c) Eurotium chevalieri.

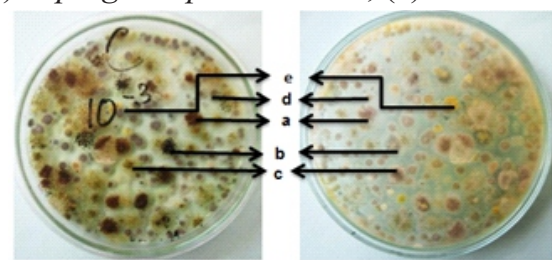

Gambar 3. Koloni sampel C pada cawan petri permukaan atas (kiri), pada permukaan bawah (kanan), (a) Aspergillus tamarii, (b) Aspergillus niger, (c) Aspergillus oryzae, (d) Aspergilus penicilloides, (e) Eurotium chevalieri

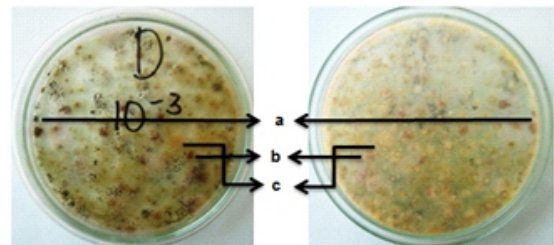

Gambar 4. Koloni sampel D pada cawan petri permukaan atas (kiri), pada permukaan bawah (kanan), (a) Aspergillus niger, (b) Aspergillus tamarii, (d) Aspergillus oryzae. 


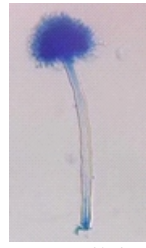

A. candidus

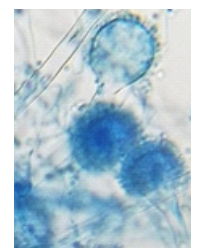

E. herbariorum

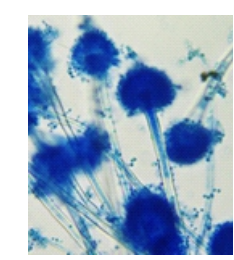

A. ochraceus

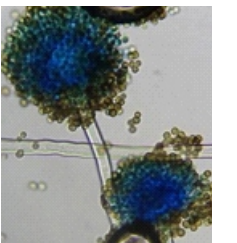

A.tamarii

Gambar 5 .

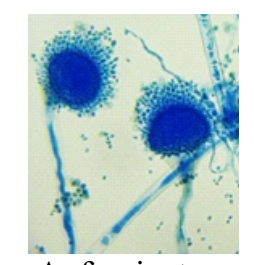

A. fumigatus

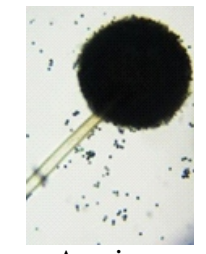

A. niger

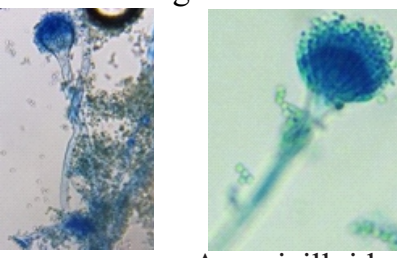

E. chevalieri A.penicilloides

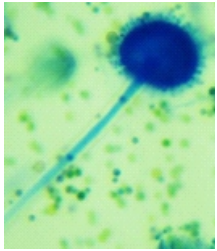

A.oryzae

Tabel 5. Spesies jamur dan potensinya dalam menghasikanmiko toksin

\begin{tabular}{cll}
\hline No & \multicolumn{1}{c}{ Spesies } & \multicolumn{1}{c}{ Toksin yang dihasilkan } \\
\hline 1 & Aspergillus candidus & Kojic acid \\
\hline 2 & Aspergillus ochraceus & Penicillic acid, ochratoxin A, xanthomeginin, viomellein, vioxanthin \\
\hline 3 & Aspergillus fumigatus & Gliotoxin, verrucologen, fumitremorgin A\&B \\
\hline 4 & Eurotium herbariorum & - \\
\hline 5 & Aspergilus tamarii & Cyclopiazonic acid, kojic acid \\
\hline 6 & Eurotium chevalieri & - \\
\hline 7 & Aspergillus penicilloides & - \\
\hline 8 & Aspergillus niger & Ochratoxin A \\
\hline 9 & Aspergillus oryzae & Cyclopiazonic acid, 3-nitropropionic acid \\
\hline
\end{tabular}

Sumber : (Rukmini, 2009).

\section{B. Pembahasan}

Hasil penelitian menunjukan bahwa dari semua sampel lada bubuk yang diidentifikasi terkontaminasi jamur xerofilik. Spesies jamur xerofilik yang ditemukan bervariasi pada seluruh sampel. Hasil identifikasi jamur xerofilik pada lada bubuk didapatkan jamur Aspergillus candidus, Aspergillus ochraceus, Aspergillus fumigatus, Eurotium herbariorum, Aspergillus tamarii, Eurotium chevalieri, Aspergillus penicilloides, Aspergillus niger, dan Aspergillus oryzae.

Seluruh sampel lada bubuk terkontaminasi oleh jamur xerofilik, hal ini mungkin terjadi karena pada proses pengolahan lada masih dilakukan dengan cara yang kurang higienis, alat dan bahan-bahan yang digunakan kurang bersih, serta adanya bahan-bahan lain yang diikutkan dalam proses penggilingan lada bubuk. Perbedaan jenis spesies yang ditemukan pada masing-masing sampel dapat disebabkan oleh kadar air lada yang terlalu tinggi akan mengakibatkan banyaknya kontaminasi pada bahan, lingkungan penyimpanan atau kemasan yang kurang memenuhi persyaratan, sehinggga dapat menyebabkan terjadinya peningkatan kadar air dan kelembaban udara.

Dari 9 jamur yang ditemukan, 6 di antaranya berpotensi sebagai penghasil mikotoksin, jenis toksin yang dihasilkan itujukkan di Tabel 5.

Kehadiran jamur xerofilik yang berpotensi menghasilkan mikotoksin pada lada bubuk perlu mendapatkan perhatian, mengingat bahwa lada merupakan rempah-rempah yang sering digunakan oleh masyarakat. Kondisi optimum untuk produksi mikotoksin adalah pada kadar air $18-30 \%$, suhu $30-40^{\circ} \mathrm{C}$ dan $\mathrm{Rh} 85 \%$ (Rukmini, 2009).

Pengujian kadar air pada masing-masing sampel lada bubuk bertujuan untuk memperkuat data hasil identifikasi. Jamur xerofilik adalah jamur yang mampu tumbuh pada produk kering dengan $\mathrm{a}_{\mathrm{w}}<0,80$, untuk itu perlu diketahui berapa nilai $a_{w}$ pada masing- 
masing sampel lada bubuk. Uji kadar air lada bubuk pada sampel A, didapatkan hasil $12,59 \%$, jadi sampel A memiliki nilai $\mathrm{a}_{\mathrm{w}} 0,12$. Uji kadar air lada bubuk pada sampel B, didapatkan hasil 11,64\%, jadi sampel B memiliki nilai $\mathrm{a}_{\mathrm{w}} 0,11$. Uji kadar air lada bubuk pada sampel C, didapatkan hasil 15,70\%, jadi sampel C memiliki nilai $\mathrm{a}_{\mathrm{w}} 0,15$. Uji kadar air lada bubuk pada sampel D, dida-patkan hasil $13,57 \%$, jadi sampel D memiliki nilai $\mathrm{a}_{\mathrm{w}} 0,13$. Dari semua hasil yang diperoleh, keseluruhan sampel lada bubuk, sampel A, B, C dan D memiliki nilai $\mathrm{a}_{\mathrm{w}}<0,80$, sehingga jamur yang tumbuh pada semua sampel adalah jamur xerofilik.

Sifat fisiologis dari masing-masing jamur yang ditemukan yaitu: Aspergillus candidus tumbuh optimum pada suhu dari $20-24^{\circ} \mathrm{C}$ sampai $45-50^{\circ} \mathrm{C}$, suhu paling rendah untuk pertumbuhan mulai dari $3-4^{\circ} \mathrm{C}$ sampai $11-13^{\circ} \mathrm{C}$, dan suhu paling tinggi pertumbuhan nya pada 41-42 ${ }^{\circ} \mathrm{C}$ sampai $50-55^{\circ} \mathrm{C}$. Aspergillus candidus tidak mampu tumbuh pada suhu $37^{\circ} \mathrm{C}$. Optimum untuk pertumbuhan adalah $\mathrm{a}_{\mathrm{w}}>0,98 . \mathrm{A}_{\mathrm{w}}$ minimum untuk pertumbuhan Aspergillus candidus adalah $\mathrm{a}_{\mathrm{w}}$ 0,75. Spesies Aspergillus candidus ini merupakan kapang gudang karena sering ditemukan pada serealia yang kering yang disimpan dalam jumlah besar di gudang (Gandjar et al., 2000).

Aspergillus ochraceus tumbuh optimum pada $\mathrm{a}_{\mathrm{w}}$ 0,95-0,99, dan $\mathrm{a}_{\mathrm{w}}$ minimum untuk pertumbuhan adalah 0,79 dalam suhu $25^{\circ} \mathrm{C}$. Dapat tumbuh dengan baik pada $\mathrm{pH} 3-10$, tumbuh lambat pada $\mathrm{pH}$ 2,2. Suhu paling tinggi untuk pertumbuhan yaitu $37^{\circ} \mathrm{C}$, sedangkan suhu paling rendah untuk pertumbuhan yaitu $40^{\circ} \mathrm{C}$. Aspergillus ochraceus dapat menghasilkan mikotoksin yang bersifat toksigenik (Pitt dan Hocking, 2009). Spesies Aspergillus ochraceus ini sering ditemukan pada biji-bijian kopi, rempah-rempah, dan bahan-bahan kering lain nya yang disimpan di gudang (Gandjar et al., 2000).
Aspergillus fumigatus ini mampu tumbuh pada $\mathrm{a}_{\mathrm{w}} 0,82$. Suhu paling rendah untuk pertumbuhan yaitu $12^{\circ} \mathrm{C}$, optimum nya $40-42^{\circ} \mathrm{C}$ dan paling tinggi pada $55^{\circ} \mathrm{C}$. Aspergillus fumigatus adalah agen utama aspergillosis pada paru-paru yang menginfeksi pria dan juga burung. Aspergillus fumigatus dapat di temukan pada kacang-kacangan, camilan-camilan dari jagung, lada, bawang kering, susu dan keju (Pitt dan Hocking, 2009).

Eurotium herbariorum adalah xerofilik yang kuat. Spesies ini tumbuh dapat tumbuh baik pada $a_{w}<0,85$. Pertumbuhan optimum nya yaitu pada $a_{w} 0,80-0,85$. Pertumbuhan paling rendahnya pada $\mathrm{a}_{\mathrm{w}} 0,64$ pada suhu $28^{\circ} \mathrm{C}$. Ascospora $E$. herbariorum dapat berkecambah pada $\mathrm{a}_{\mathrm{w}} 0,74$. Spesies ini mampu tumbuh dalam kadar oksigen yang rendah. Habitat Eurotium herbariorum yaitu pada jagung, beras, produk daging, sarden, rempah-rempah dan kacang-kacangan seperti kacang kedelai. Spesies ini langka dan masih sulit untuk di kenali, karena cleistothecia nya berwarna putih dan menghasilkan anamorph nya hanya pada $\mathrm{a}_{\mathrm{w}}$ yang sangat rendah (Pitt dan Hocking, 2009).

Aspergillus tamarii mampu tumbuh pada $\mathrm{a}_{\mathrm{w}}$ $<0,78$, dan pada suhu $33^{\circ} \mathrm{C}$. Spesies ini merupakan kapang tropis yang sangat umum, dan banyak ditemukan pada rempah-rempah, jagung, serealia, tanah dan udara (Gandjar et al., 2000).

Eurotium chevalieri tumbuh optimal pada $\mathrm{a}_{\mathrm{w}}$ 0,94-0,95. Suhu optimum untuk pertumbuhan Eurotium chevalieri adalah $30-35^{\circ} \mathrm{C}$ dan suhu maksimum untuk pertumbuhan nya adalah 40$43^{\circ} \mathrm{C} . \mathrm{A}_{\mathrm{w}}$ paling rendah untuk pertumbuhan yaitu 0,74 pada $25^{\circ} \mathrm{C}$ pada media dengan $\mathrm{pH} 3,8$. Askospora spesies ini mengkontaminasi kacang-kacangan, kemiri, ikan asin, tepung beras, jagung dan sayuran (Pitt dan Hocking, 2009).

Tingkat optimal untuk pertumbuhan Aspergillus penicilloides adalah $\mathrm{a}_{\mathrm{w}} 0,89$, pada suhu $30^{\circ} \mathrm{C}$, dan pada $\mathrm{pH} 5,5$ dalam glukosa atau fruktosa. Tumbuh optimum juga pada $\mathrm{a}_{\mathrm{w}} 0,91$ - 
0,93, pada suhu $25^{\circ} \mathrm{C}$, pH 6,5 pada media yang mengandung glukosa atau fruktosa atau $\mathrm{NaCl}$. Aspergillus penicillioides mampu berkecambah tapi tidak dapat tumbuh pada suhu $25^{\circ} \mathrm{C}, \mathrm{a}_{\mathrm{w}} 0,70$ dan $\mathrm{pH}$ 4,5-5,5 media yang mengandung glukosa/fruktosa. Aspergillus penicillioides pada masih cukup langka dan sulit ditemukan, terutama karena tidak tumbuh pada media yang biasa digunakan untuk isolasi jamur. Pertumbuhan baik pada media yang memiliki $\mathrm{a}_{\mathrm{w}}$ rendah seperti DG18. Aspergillus penicillioides, seringkali terdapat pada beragam makanan, termasuk tepung, buah kering, ikan kering, dari rempahrempah, termasuk lada dan cabai kering (Pitt dan Hocking, 2009).

Aspergillus niger dapat tumbuh pada $\mathrm{a}_{\mathrm{w}} 0,77$, $\mathrm{pH}$ 2,0. Dan suhu minimum untuk pertumbuhan Aspergillus niger $6-8^{\circ} \mathrm{C}$, maksimum $45-47^{\circ} \mathrm{C}$, dan optimum $35-37^{\circ} \mathrm{C}$. Aspergillus niger lebih banyak ditemukan di iklim yang lebih hangat, Spora hitam memberi perlindungan dari sinar matahari dan sinar UV (Pitt dan Hocking, 2009). Spesies ini kosmopolit di daerah tropis dan subtropis, dan mudah diisolasi dari tanah, udara, air, rempah-rempah, kapas, buah-buahan, gandum, beras, jagung, tebu,kopi, teh, coklat, serta dedaunan (Gandjar et al., 2000).

Aspergillus oryzae tumbuh pada suhu paling rendah $12^{\circ} \mathrm{C}$, tumbuh pada suhu paling tinggi pada $48^{\circ} \mathrm{C}$ dan tumbuh optimal pada suhu 25 $42^{\circ} \mathrm{C}$. $\mathrm{pH}$ optimum nya yaitu 7,5 , sedangkan $\mathrm{a}_{\mathrm{w}}$ paling rendah untuk pertumbuhan yaitu 0,78 . Aspergillus oryzae sulit dibedakan dengan Aspergillus flavus, karena kedua nya memiliki ciri-ciri yang hampir sama. Aspergillus flavus memiliki koloni dengan ukuran yang sama atau sedikit lebih kecil dibandingkan dengan Aspergillus oryzae. Koloni A. oryzae berubah pada warna konidia nya dari hijau ke arah coklat zaitun dengan terus Inkubasi pada suhu $25^{\circ} \mathrm{C}$ selama 7-14 hari. Sedangkan koloni A. flavus tetap hijau kuning atau menjadi hijau keabuabuan. Spesies A. oryzae dapat ditemukan pada jagung, kedelai, kacang tanah, kacang hitam, rempah-rempah (Pitt dan Hocking, 2009), dan dapat ditemukan pada aneka substrat, terutama pada makanan fermentasi di kawasan Asia, serta pada lingkungan industri (Gandjar et al., 2000).

\section{KESIMPULAN}

Lada bubuk bermerk dan tidak bermerk terkontaminasi jamur xerofilik. Spesies jamur xerofilik yang terdapat pada lada bubuk yaitu Aspergillus candidus, Aspergillus ochraceus, Aspergillus fumigatus, Eurotium herbariorum, Aspergillus tamarii, Eurotium chevalieri, Aspergillus penicilloides, Aspergillus niger, dan Aspergillus oryzae. Dari 9 spesies jamur yang ditemukan, 6 diantaranya dapat berpotensi sebagai penghasil mikotoksin.

\section{DAFTAR PUSTAKA}

Acumedia. 2011. "Dichloran Glycerol (DG-18) Agar Base (7592)"

Biokar diagnostics. 2010. "Dichloran Glycerol (DG18) Agar"

Gandjar, I., Sjamsuridzal, W., Oetari, A. 2006. Mikologi Dasar dan Terapan. Jakarta: Yayasan Obor Indonesia.

Gandjar, I., Samson, R.A., Taweel-Vermeulen, K.V., Oetari, A., Santoso, I. 2000. Pengenalan Kapang Tropik Umum. Jakarta: Yayasan Obor Indonesia.

Ghofur, A. 2006. "Identifikasi Jamur Kontaminan pada Susu Kambing Berdasarkan Perbedaan Suhu Dingin”. Skripsi. Yogyakarta: Universitas Gajah Mada.

Hidayat, T., Nurdjannah, N., Usmiati, S., 2009. “Analisis Teknis dan Finansial Paket Teknologi Pengolahan Lada Putih (White Pepper) Semi Mekanis". Jurnal Teknologi dan Industri Pangan, 20(1):77-91.

Maryam, R. 2014. "Pengendalian Terpadu Kontaminasi Mikotoksin". 16(1):21-30

Pitt, J.I., dan Hocking A.D. 2009. Fungi and Food Spoilage. New York: Springer Science+Business Media.

Rahayu, Endang S. 2007. "Mewaspadai Cemaran Mikotoksin". Majalah Ilmiah. FOODREVIEW, Vol II (8):46-49.

Rukmi, I. 2009. "Keanekaragaman Aspergillus pada Berbagai Simplisia Jamu Tradisional". Jurnal Sains \& Matematika (JSM), 17 (2) : 82-89.

Samson, R.A., Hoekstra, E.S., dan Oorschot, C.A.N.V. 1984 Introduction to Food-Borne Fungi. Netherland: Academy of Arts and Sciences.

Saparinto, C., dan Susiana, R. 2016. Grow Your Own Medical Plant - Penduan Praktis Menanam 51 Tanaman Obat Populer di Pekarangan. Yogyakarta: LILI PUBLISHER.

Toto, H.H. 2013. "Usaha Tani Lada (Piper nigrum Linn.) di Desa Sahan Kecamatan seluas Kabupaten Bengkayang Kalimantan Barat". Skripsi. Yogyakarta: Fakultas Ilmu Sosial, Universitas Negeri Yogyakarta. 